\title{
GERAKAN REFORMASI 1998 DI KECAMATAN KALIWATES KABUPATEN JEMBER (PENGRUSAKAN TOKO MILIK ETNIS CINA)
}

\author{
Noviyanti*, Rully Putri Nirmala Puji, Wiwin Hartanto \\ Program Studi Pendidikan Sejarah, Jurusan Pendidikan IPS, FKIP - Universitas Jember
}

\begin{tabular}{l}
\hline Article History \\
\hline Submitted: May 23, 2019 \\
Accepted : May 28, 2019 \\
Published : August 8, 2019
\end{tabular}

\begin{tabular}{l}
\hline Kata Kunci \\
\hline Gerakan Reformasi, etnis \\
Cina, Kerusuhan.
\end{tabular}

\begin{abstract}
Abstrak
Kerusuhan Mei 1998 merupakan salah satu peristiwa bersejarah dalam perjalanan bangsa, peristiwa ini memberikan dampak yang kompleks terhadap semua lapisan masyarakat yang mengalaminya di berbagai daerah salah satunya adalah etnis Cina. Etnis Cina kerap menjadi sasaran dalam kerusuhan tersebut seperti di daerah Situbondo terjadi kerusuhan anti Cina pada tahun 1967 yang disebabkan oleh kesenjangan politik dan ekonomi serta di beberapa daerah lain. Berdasarkan data dan fakta empiris tersebut penulis tertarik untuk menelusuri apakah di Kecamatan Kaliwates Kabupaten juga terjadi perusakan terhadap toko-toko milik etnis Cina sebagai rangkaian dari gerakan reformasi atau tidak mengingat banyaknya masyarakat etnis Cina di kecamatan ini. Metode kajian yang digunakan adalah metode sejarah dengan pengumpulan data berupa teknik wawancara kepada beberapa informan Berdasarkan wawancara yang telah dilakukan, informasi yang dapat diperoleh yaitu kerusuhan (demonstrasi) pada tahun 1998 di Kecamatan Kaliwates terjadi di kawasan Jalan Gajah Mada hingga kantor Pemerintah Daerah Jember, Peristiwa ini juga disertai dengan pengrusakan terhadap beberapa toko milik etnis Cina. Peristiwa ini menimbulkan ketakutan dan rasa tidak aman bagi masyarakat etnis Cina untuk melakukan aktivitas jual beli. Peristiwa ini terjadi sebagai akibat dari kekagetan/ euforia terhadap situasi politik dan sosial yang sedang tidak stabil.
\end{abstract}

\section{PENDAHULUAN}

Kerusuhan Mei 1998 merupakan salah satu peristiwa dari serangkaian sejarah lahirnya Reformasi. Latar belakang terjadinya peristiwa ini adalah krisis moneter yang melanda Asia dan dunia serta dipicu oleh kebobrokan dalam berbagai aspek baik ekonomi, politik, dan pemerintahan. Kurs Rupiah jatuh, harga bahan pokok melonjak, jumlah impor meningkat dan lain sebagainya (Rahman, 2013, p. 89).

Peristiwa Mei 1998 dijadikan kesempatan untuk menuntaskan sentimen terhadap etnis Cina. Sebenarnya sentimen terhadap etnis Cina ini sudah lama terjadi, dari segi historis dalam buku Jakarta: Sejarah 400 Tahun karya Susan Blackburn dituliskan, masyarakat etnis Cina sudah ada sebelum kedatangan Belanda. Masyarakat etnis Cina dimanfaatkan sebagai rekan bisnis dan mendapatkan perlakuan istimewa ketimbang kebanyakan masyarakat setempat sehingga menimbulkan kecemburuan sosial (Blackburn, 2011). Hal ini membuktikan bahwa ada sentimen tertanam dan terus berlanjut hingga pada peristiwa Perang Jawa (1825-1830).

Banyak orang Cina yang dibunuh tak peduli anak-anak atau perempuan. Mereka dibunuh dan tubuh-tubuh yang terpotong dibiarkan di jalanan. Kebencian ini 
mendarah daging, menyebar luas, tanpa sempat ada rekonsiliasi atau penjelasan. Tragedi terhadap masyarakat etnis Cina berikutnya terjadi pada saat 1965 . Banyak masyarakat etnis Cina saat itu yang menjadi korban karena dianggap komunis atau mata-mata Tiongkok.

Kerusuhan Mei 1998 yang terjadi selama tiga hari di Indonesia ini telah menghancurkan toko dan perusahaan terutama milik warga keturunan Cina di mana konsentrasi terbesar terjadi di Jakarta. Peristiwa ini diduga juga terdapat kejahatan manusia, ada laporan yang menyebutkan terjadi tindak pelecehan seksual bahkan pemerkosaan terhadap perempuan etnis keturunan Cina dan menunjukan ada indikasi bahwa kasus pemerkosaan dalam kerusuhan ini digerakkan secara sistematis. Sentimen rasial tersebut terlihat dalam beberapa bentuk seperti: tulisan-tulisan pada tembok atau kain yang berisi kata-kata makian, kata-kata makian yang menyertai aksi-aksi kerusuhan, pemeriksaan ("sweeping") terhadap etnis Cina, pemilihan sasaran-sasaran perusakan atau penjarahan terhadap barang atau bangunan milik etnis Cina, tulisantulisan di tembok atau di kain bertuliskan seperti "milik pribumi", "muslim", dan sebagainya (Hutahaean, 2014, p. 29).

Di Situbondo juga terjadi kerusuhan anti Cina pada tahun 1967 yang disebabkan oleh kesenjangan politik dan ekonomi (Winarni \& Badriyanto, 2012, p. 144). Kasus ini menjadi bukti dari simpulan yang dikemukakan oleh Rahman yang menutip pendapat dari Kelden bahwa kekerasan dan kerusuhan terhadap suatu etnis tertentu tidak tidak bersifat murni kebencian pada satu jenis etnis itu, melainkan karena terjadi dominasi politik dan ekonomi oleh etnik satu terhadap etnik yang lain. Puncak dari pelampiasan sentimen terhadap etnis Cina ini terjadi pada peristiwa reformasi 1998. Saat itu etnis Cina menjadi korban kekerasan, penjarahan dan diskriminasi hebat (Rahman, 2013, p. 178).

Kasus serupa pada tahun yang sama (1998) tidak hanya terjadi di kota Jakarta tetapi juga dibeberapa daerah lain di Indonesia. Peristiwa ini terjadi di daerah Petukangan, Taman Sari, Padang, Situbondo, dan Bondowoso (Kurniawan \& Suwirta, 2016, p. 55). Kerusuhan/konflik ini sudah diteliti dan dikaji dari aspek kronologis dan historis yang melatarbelakanginya. Di Situbondo, kajian difokuskan pada konflik laten yang timbul akibat kesenjangan sosial dan ekonomi namun tidak dipaparkan secara mendetail bagaimana kronologis peristiwa pengrusakan terhadap etnis Cina itu terjadi. Penulis tertarik untuk membahas kronologis peristiwa kerusuhan sentimen anti Cina utamanya berkaitan dengan pengrusakan yang dilakukan di beberapa toko milik Etnis Cina yang banyak tersebar di Kecamatan Kaliwates Kabupaten Jember.

\section{METODE DAN FOKUS PENELITIAN}

Metode yang digunakan dalam penelitian ini adalah metode sejarah yang meliputi heuristik berupa pengumpulan sumber dari wawancara dan studi pustaka. Selanjutnya adalah kritik untuk menilai apakah sumber sejarah berupa wawancara tersebut akurat atau tidak. Kritik diklasifikasikan menjadi dua yaitu kritik intern dan kritik ekstern. Kemudian peneliti melakukan interprestasi atau penafsiran terhadap sumber sejarah yang telah diperoleh. Proses terakhir adalah historiografi yaitu tahap penyusunan fakta sejarah menjadi cerita sejarah yang dapat dipertanggungjawabkan. Pada tahap ini peneliti menyajikan hasil penelitian dalam bentuk wawancara dilakukan 
terhadap beberapa saksi yang melihat langsung kejadian pengrusakan terhadap tokotoko milik etnis Cina yang berada di sepanjang jalan protokol di Kecamatan Kaliwates Kabupaten Jember.

Ruang lingkup penelitian sangat penting untuk tujuan agar peneliti tidak menyimpang dari permasalahan yang diteliti. Untuk itu peneliti perlu untuk membatasi permasalahan khususnya mengenai tempat (spasial), waktu (temporal), dan fokus kajian (Laily, 2016, p. 1). Louis Gotschalk juga berpendapat bahwa pembatasan ruang lingkup ini penting agar dapat mempunyai proporsi yang sedemikan rupa sehingga mengenai hal yang diteliti dapat menulis sesuatu yang tidak akan mudah diperoleh dari sejumlah buku lain (Kuntowijoyo, 1995).

Ruang lingkup tempat (spasial) yang digunakan dalam penelitian ini adalah Kecamatan Kaliwates Kabupaten Jember. Ketertarikan penulis untuk mengkaji di wilayah ini telah dipaparkan pada uraian sebelumnya. Ruang lingkup waktu (temporal) yang digunakan pada penelitian ini adalah tahun 1998. Alasan pemilihan tahun 1998 sebagai ruang lingkup temporal penelitian karena gerakan reformasi yang dibarengi oleh tindak kekerasan terhadap etnis Cina terutama pengrusakan terhadap toko-toko terjadi pada tahun tersebut.

\section{HASIL DAN PEMBAHASAN}

Berdasarkan hasil wawancara kepada beberapa informan, diperoleh fakta berupa urutan kronologis peristiwa pengrusakan itu terjadi. Ibu Sharon Yudiani (73 tahun), seorang Cina pemilik toko lampu (Toko Sinar di Jalan Sultan Agung, Kecamatan Kaliwates, Kabupaten Jember) yang sudah berdiri sejak 1965 menceritakan bahwa pada tanggal 12 Mei 1998, ada sekumpulan massa yang turun ke jalan dan mengadakan demonstrasi dari Jalan protokol Gajah Mada hingga kantor Pemerintah Daerah Kabupaten Jember. Sekumpulan massa ini melakukan pengrusakan dengan cara melempari batu dan mengakibatkan bagian depan toko milik etnis Cina rusak dan pecah.

Massa berkumpul pada siang hari utamanya pada hari Jumat. Ibu Sharon Yudiani (73 tahun) memberikan keterangan bahwa orang-orang yang melakukan pengrusakan berasal dari luar daerah Jember kota dan umumnya tidak dikenal (bukan orang sekitar). Bapak Hong Sui (83 tahun) seorang Cina pemilik toko alat-alat tulis di Jalan Trunojoyo juga memberi keterangan bahwa kerusuhan itu dilakukan oleh orang-orang yang berasal dari kecamatan lain seperti Tanggul dan Sumberbaru. Mereka bahkan sempat berhenti di depan toko Bapak Hong Sui dan meminta air minum. Beberapa saat setelah sekumpulan massa ini pergi, ada warga sekitar yang memberitahukan bahwa telah terjadi kerusuhan dan bapak Hong Sui segera menutup toko miliknya.

Pengrusakan tidak berhenti sampai disini saja, bahkan ada salah satu toko milik etnis Cina yang dibakar oleh massa tersebut. Bapak Andy (35 tahun) adalah salah satu saksi mata ketika pembakaran terhadap toko Sumber Mas di Jalan Trunojoyo. Kebakaran menimbulkan kegaduhan dan keresahan dari warga karena khawatir kebakaran tersebut akan merembet ke pemukiman penduduk. Kebakaran ini mengakibatkan toko tersebut rusak parah. Diduga, kebakaran tersebut sengaja menurut Bapak Andy (35 tahun) dilakukan oleh segerombolan massa tersebut mengingat tidak 
ada bekas kosleting listrik yang diketahui. Toko Sumber Mas tersebut saat ini sudah tidak beroperasi lagi.

Dampak yang dirasakan oleh etnis Cina terhadap kejadian tersebut adalah dampak psikologis dan dampak ekonomi. Ibu Sahron Yudiani (73 tahun) mengatakan bahwa selama beberapa hari pasca kejadian tersebut ia tidak berani membuka tokonya. Ibu Sharon tidak berani melakukan aktivitas apapun diluar rumah termasuk berjualan karena khawatir peristiwa pengrusakan dan pembakaran serupa akan terjadi lagi. Hal serupa juga dirasakan oleh Bapak Hong Sui yang juga menutup tokonya hingga beberapa hari. Hampir setiap hari terdengar tembakan senjata dari aparat yang diduga untuk membubarkan massa yang sering membuat kegaduhan. Kejadian tersebut memberikan dampak yang merugikan bagi Bapak Hong Sui karena rasa takut untuk membuka toko dan melakukan aktivitas penjualan seperti biasanya.

Selain dampak psikologis, ada pula dampak ekonomi yang dirasakan oleh mereka, pendapatan turun karena toko yang sering tutup dan sepinya pelanggan. Toko yang sering tutup menyebabkan penghasilan juga turun. Bapak Hong Sui memberikan keterangan tambahan bahwa kondisi perekonomianan sangat susah karena toko-toko sering tutup, penurunan pendapatan, dan merasa tidak aman. Peristiwa tersebut meningkatkan kewaspadaan dan kehati-hatian dari beberapa etnis Cina yang memiliki toko di kawasan kecamatan Kaliwates kabupaten Jember. Selain itu, para pemilik toko ini juga kesulitan untuk membeli barang-barang untuk persediaan toko karena kondisi ekonomi yang tidak menentu serta keadaan yang belum sepenuhnya kondusif.

Hendratmoko (dalam Winarni dan Samsu, 2012:155) berpendapat apabila di tempat lain, di Makassar pasca peristiwa G 30 S PKI tahun 1965 misalnya, menyebabkan semakin renggangnya hubungan antara orangorang Cina dengan penduduk pribumi, tidak demikian halnya di Situbondo. Menurut beberapa informan, di antaranya pascakerusuhan tahun 1998 hubungan antara orang-orang Cina dengan penduduk pribumi biasa-biasa saja. Hal itu juga serupa dengan keadaan yang ada di Kecamatan Kaliwates Kabupaten Jember.

Seperti yang telah dijelaskan diatas bahwa massa yang melakukan kerusuhan ini berasal dari dari luar Jember kota, karena menurut keterangan dari kedua informan yaitu Ibu Sharon Yudiani (73 tahun) dan bapak Hong Sui (83 tahun), hubungan mereka dengan warga lokal sekitar terbilang baik dan rukun, bahkan sudah mulai ada integrasi di antara dua etnis yang berbeda ini dalam kegiatan sehari-hari.

\section{PENUTUP}

Dari uraian yang diatas dapat disimpulkan bahwa di Kecamatan Kaliwates Kabupaten Jember juga terjadi kerusuhan sebagai rentetan dari Gerakan Reformasi 1998 seperti wilayah-wilayah lain di Indonesia meskipun tidak semasif seperti wilayah lain. Kerusuhan yang terjadi umumnya berupa pengrusakan dan pembakaran terhadap tokotoko milik etnis Cina. Peristiwa ini dapat dikatakan sebagai bentuk euforia/kekagetan terhadap situasi politik yang sedang berlangsung, bukan karena sentimen anti Cina dan kecemburuan ekonomi seperti kebanyakan pendapat yang dikemukakan karena hubungan antara etnis Cina dan warga sekitar berlangsung dengan baik dan rukun. 
Euforia/kekagetan ini dimanfaatkan oleh oknum-oknum tertentu untuk memperkeruh situasi dan kondisi yang terjadi pada tahun 1998.

\section{REFERENSI}

Blackburn, S. (2011). Jakarta: Sejarah 400 Tahun. (G. Triwira, Trans.). Depok: Masup Jakarta.

Hutahaean, J. (2014). Dampak Kerusuhan Mei 1998 terhadap Pengusaha Etnis Tionghoa di Petukangan Jakarta Tahun 1998-2003. Journal of Indonesia History, 3(1), 27-33.

Kuntowijoyo. (1995). Metode Sejarah. Yogyakarta: Tiara Wacana.

Kurniawan, M. D., \& Suwirta, A. (2016). Ideologisasi Konsep Reformasi dalam Historiografi Buku Teks Pelajaran Sejarah di Sekolah. MIMBAR PENDIDIKAN, 1(1), 55. https://doi.org/10.17509/mimbardik.vii1.1753

Laily, K. N. (2016). Dinamika Kehidupan Sosial-Ekonomi Etnis Tionghoa di Makassar pada Masa Orde Baru (1966-1998). Universitas Jember.

Rahman, N. E. (2013). Konflik dan Kecemburuan Sosial antara Etnis Tionghoa dan Masyarakat Pandhalungan di Daerah Besuki - Situbondo. In The 5th International Conference on Indonesian Studies: "Ethnicity and Globalization.” Yogyakarta: Fakultas Ilmu Budaya Universitas Indonesia.

Winarni, R., \& Badriyanto, B. S. (2012). Kerusuhan Anti-Cina di Kabupaten Situbondo Tahun 1967. MOZAIK: Jurnal Ilmu Humaniora, 12(2), 141-156. 